Obere Extremität 2019 · 14:118-126 https://doi.org/10.1007/s11678-019-0508-2 Received: 16 October 2018

Accepted: 23 January 2019

Published online: 21 February 2019

(c) The Author(s) 2019

\begin{abstract}
Combined glenohumeral fractures of the humeral head and the glenoid are rare fracture combinations and their treatment depends on different criteria. When treating these fractures, one has to consider the fracture morphology of both fracture localizations at the proximal humerus, on the one hand, and at the glenoid, on the other hand. In terms of fracture localization, greater tuberosity fractures can be distinguished from proximal humerus fractures (with subcapital fracture component), both of which may occur with glenoid fractures. On the glenoid side, the more frequent large glenoid rim fractures and the rarer glenoid fossa fractures can be found together with a fracture of the proximal humerus.
\end{abstract}

In recent decades, proximal humerus fractures have been intensively researched, which is reflected by numerous publications in the literature $[1,6,7,11$, $18-20,23-25,27,31,32,38,41,42$, $48-50,53]$. Glenoid fractures have also been considered in a more differentiated manner in recent years and relevant studies have been published $[2,4,9,15$, $21,22,26,28,33,34,45,46,51]$. However, only few data are available about simultaneously occurring (combined) glenohumeral fractures, and their specific therapy in the literature is mostly described as isolated cases in studies focusing on glenoid fractures or in case reports $[12,28,33,37,39,51]$. These combination fractures potentially involve the anterior glenoid rim (Ideberg et al:: 1B [15], Euler-Rüedi: D1 [10], Scheibel et al.: $1 \mathrm{~b} / \mathrm{c}[47])$ and the glenoid

M. Königshausen · E. Mempel • V. Rausch • J. Gessmann · T. A. Schildhauer · D. Seybold

General and Trauma Surgery, BG University Bergmannsheil, Ruhr University Bochum, Bochum, Germany

\title{
Combined fractures of the humeral head and the glenoid
}

fossa fractures (Ideberg et al.: II-V, Euler-Rüedi: D2/3) combined with greater tuberosity or proximal humerus fractures (Neer I-VI), and all combined glenohumeral fractures are potentially summarized in one type of combination fracture as type E Euler-Rüedi [10].

The aim of the present baseline study was to analyze all the different fracture types of the glenoid and the humeral head in combined glenohumeral fractures using a specific classification for these fractures. Furthermore, the morphology of the fracture is evaluated, the choice of treatment is demonstrated, and any complications encountered during follow-up are described. In addition, a summary of the existing literature about glenohumeral fractures is given.

\section{Patients and methods}

\section{Data collection}

All combined fractures of the proximal humerus and the glenoid were reviewed retrospectively using an institutional database (Bergmannsheil Bochum, Ruhr University, Level I trauma center) covering the period 1998-2016. All glenohumeral fractures identified on the humeral side were differentiated into proximal humerus fractures (and the respective number of fracture parts derived by Codeman [8] and Neer [35]) or only isolated greater tuberosity fractures (one or two fragments or comminuted) and into large fractures of the glenoid rim (one or two fragments or comminuted) or glenoid fossa fractures (Ideberg et al. classification [15]). The authors define a glenoid rim fracture as an isolated fracture of the glenoid (without the scapula) with the exclusive involvement of the cancellous part of the glenoid (including the glenoid cortical wall). The "large" glenoid rim fracture must be differentiated from small chip fractures, which usually consist of only a small cortical fragment $[34,54]$. By contrast, the fossa fracture is defined as a glenoid fracture with its extension into (the cortex of) the scapula (e.g., including the lateral, medial, or superior border [margo medialis/lateralis/ superior] or coracoid process).

\section{Fracture classification}

We divided "glenohumeral combination fractures" into four types in a classification shown in - Table 1. This classification takes into account the increasing size/severity of the glenohumeral fracture parts involved. The very rare additional coracoid process fracture, which can occur simultaneously with an anterior glenoid rim fracture and a greater tuberosity fracture, was not seen at our hospital but is described in case reports or case series $[40,52]$ and is subsumed as type $1 b$.

Fracture characteristics and morphology were distinguished and the degree of displacement of the glenoid fracture and the isolated greater tuberosity fracture was measured (in millimeters). Glenoid fractures were defined as having no or mild displacement $(0-3 \mathrm{~mm})$ or as displaced ( $\geq 4 \mathrm{~mm}$; [22]). There is no consistent and clear definition of displacement of the greater tuberosity fracture in the literature. The authors generally use three categories of greater tuberosity fracture displacement in which a "moderate" displacement is considered because 


\section{Table 1 Classification of glenohumeral combination fractures}

Type 1a: Large glenoid rim fracture (GRF) AND greater tuberosity fracture (GTF)

Type 1b: Typ 1a with additional coracoid process fracture (CPF)

Type 2: Large glenoid rim fracture (GRF) AND proximal humerus fracture (PHF)

Type 3: Glenoid fossa fracture (GFF) AND greater tuberosity fracture (GTF)

Type 4: Glenoid fossa fracture (GFF) AND proximal humerus fracture (PHF)

of its controversial indication for therapy. Thus, tuberosity fractures between 0 and $2 \mathrm{~mm}$ were defined as mild or nondisplaced, those between 3 and $4 \mathrm{~mm}$ were defined as moderately displaced, and those of $\geq 5 \mathrm{~mm}$ were defined as displaced.

\section{Indications for surgery}

The indications for surgery of large glenoid rim fractures are under debate. We usually indicate surgery in cases of $\geq 20 \%$ anterior glenoid surface involvement in combination with medial displacement of $\geq 3 \mathrm{~mm}$ or a fracture gap of $\geq 5 \mathrm{~mm}$ (enface view) in middleaged patients. In younger individuals ( $\leq 35$ years), the indication for (usually arthroscopic) refixation is more stringent with the aim of restoring the glenoid surface to avoid re-instability. In glenoid fossa fractures we consider the limit for operative treatment to be $\geq 4 \mathrm{~mm}$ medial displacement and $\geq 4 \mathrm{~mm}$ fracture gap (enface view) because of the inferior results achieved for glenoid fossa fractures in a nonoperatively treated case series of patients with $\geq 5 \mathrm{~mm}$ displacement or $\geq 5 \mathrm{~mm}$ fracture gap [22]. The indication for surgery for greater tuberosity fractures is $\geq 4 \mathrm{~mm}$ cranial displacement and $\geq 5 \mathrm{~mm}$ posterior displacement and for proximal humerus fractures the Neer criteria [36] are applied (in addition to the 4-mm limit for cranial tuberosity displacement) with, additionally, a tilt of the humeral head of more than $20^{\circ}$. The concentricity of the humeral head is a prerequisite for nonoperative treatment in order to avoid chronic decentricity, which can occur in glenoid fractures. The criterion of concentricity can only be reliably used in combined fractures with only tuberosity fractures (type 1 and type 3), because in most cases of proximal humerus fractures (type 2 and type 4$)$ the humeral head is displaced and, therefore, cannot be used for the assessment of the centricity. However, specific patient conditions (e.g., age, comorbidities) were considered in all these indications, and in some cases, surgery was indicated individually by the treating surgeon.

\section{Follow-up}

All of the patients had initial conventional radiographs (anteroposterior [a.p.] view and axial view/Y view) and in most cases $(n=42,81 \%)$ a computed tomography scan (CT) in the initial imaging, which were all analyzed. In total, 44 patients $(85 \%)$ returned for follow-up after 25 months on average (2-168 months). Eight patients (15\%) did not return and were lost to follow-up. Within the different groups, the respective treatment (operative/nonoperative) and potential secondary interventions were analyzed regarding reason and type of surgery. In addition, detectable or documented complications during the follow-up were evaluated. Age, gender, and trauma mechanism were noted. In the case of nonoperative treatment of both fractures or one of the combined fractures, pendulum exercises were recommended for 10 days followed by passive range of motion (ROM) with up to $90^{\circ}$ abduction/flexion for 4-6 weeks. In the case of operative treatment, the standard postoperative protocol usually includes passive ROM with $60^{\circ}$ abduction/flexion for 3 weeks and subsequently $90^{\circ}$ passive ROM for a further 3 weeks; in exceptional cases, however, the treating surgeon may make individual decisions regarding the postoperative rehabilitation protocol depending on the intraoperative findings.

\section{Results}

In total, 52 patients with a combined glenohumeral fracture were identified retrospectively; type 1 glenohumeral combination fractures were the most frequent $(n=26)$ fracture type followed by type $2(n=20)$. Glenohumeral combination fractures with involvement of the glenoid fossa were rarely encountered: There were four type 3 and two type 4 glenohumeral combination fractures.

\section{Type 1}

The patients with a large glenoid rim fracture combined with a greater tuberosity fracture $(n=26)$ had an average age of 64 years (25-92 years, female: $n=14$, $n=$ male: $n=12$ ). The most frequent trauma mechanisms were shoulder dislocations in 24 cases (92\%) and a direct impact on the shoulder in two cases (8\%).

The overall displacement (coronary plane) of the large anterior glenoid rim fracture was $8.4 \mathrm{~mm}$ on average $(0-21 \mathrm{~mm})$ and the displacement in the en-face view (sagittal plane, "fracture gap") was $5 \mathrm{~mm}$ on average $(1-14 \mathrm{~mm})$. In the majority of cases $(n=21,81 \%)$, the large glenoid rim fracture consisted of one fragment (two fragments: $n=3$ [11\%], comminuted: $n=2$ [8\%]).

The greater tuberosity fracture of all shoulders with type 1 fracture was displaced by $4.5 \mathrm{~mm}$ on average $(0-20 \mathrm{~mm})$. The greater tuberosity displacement was classified as no or mild displacement in 13 patients, moderate in six, and as displaced in seven patients. Regarding the differentiation into the respective direction of the dislocation, the greater tuberosity was displaced cranially in ten (on average $3 \mathrm{~mm}$ ) of the shoulders and posteriorly in 11 ( $7 \mathrm{~mm}$; nondisplaced: $n=5, \varnothing$ $0 \mathrm{~mm}$ ). In the patient cohort, the greater tuberosity consisted of one fragment in eight patients, two fragments in four patients, and it was comminuted in most of the cases $(n=14)$.

The therapeutic management of the patients differed in the cohort. In 11 (42\%) patients, both lesions were treated nonoperatively and in nine patients (35\%) the combined fractures were treated surgically (including two older 
Obere Extremität 2019 · 14:118-126 https://doi.org/10.1007/s11678-019-0508-2

(c) The Author(s) 2019

M. Königshausen · E. Mempel · V. Rausch · J. Gessmann · T. A. Schildhauer · D. Seybold

\section{Combined fractures of the humeral head and the glenoid}

\section{Abstract}

Background. Glenohumeral combination

fractures are severe shoulder injuries for which, however, few data are available in the literature. The aim of the study was to analyze the incidence and numeric distribution of glenohumeral combination fractures using a classification system. Furthermore, treatment methods and complications are discussed.

Methods. This retrospective study is based on the data evaluation of a level I trauma center between 1998 and 2016. Glenohumeral combination fractures are classified into four types, and the incidence, treatment method, and complications are evaluated. Additionally, the fracture morphology and displacement of the different fracture types are analyzed.
Results. In total, 52 patients with a glenohumeral combination fracture were identified. There were 26 (50\%) type 1 fractures (anterior glenoid rim fracture/greater tuberosity fracture), 20 (38\%) type 2 fractures (anterior glenoid rim fractures and proximal humerus fractures), four (8\%) type 3 fractures (glenoid fossa fractures and greater tuberosity fractures), and two (4\%) type 4 fractures (glenoid fossa fractures and proximal humerus fractures). In the majority of patients $(n=25)$, both lesions of the combined fractures were treated operatively, in 15 both fractures were treated nonoperatively, and in 12 patients only one of the two lesions was treated surgically. Complications were encountered in $21 \%$ of cases, particularly on the humeral side.
Conclusion. Glenohumeral combination fractures are rare. Type 1 and type 2 fractures are the most frequent combination fractures. The indications for treatment are based on the displacement of the respective fragments, which can be addressed during the same operation if surgery is indicated. Complications are more frequently found on the humeral side.

\section{Keywords}

Glenoid cavity · Proximal humerus · Combination fractures · Fossa glenoidalis · Glenoid rim

\section{Kombinationsfrakturen von Humeruskopf und Glenoid}

\section{Zusammenfassung}

Hintergrund. Glenohumerale Kombinationsfrakturen sind schwere Schulterverletzungen, über die jedoch kaum Daten innerhalb der Literatur vorliegen. Ziel der Studie war es daher, die Inzidenz und die numerische Verteilung glenohumeraler Kombinationsfrakturen zu analysieren und anhand einer Klassifikation darzustellen. Darüber hinaus werden die Behandlungsmethoden und die einzelnen Komplikationen dargestellt.

Methoden. Die vorliegende retrospektive Studie basiert auf der Datenauswertung eines Level--Iraumazentrums zwischen 1998 und 2016. Die verschiedenen glenohumeralen Kombinationsfrakturen werden in 4 Typen eingeteilt und die Inzidenz, Behandlungsweise und Komplikationen im weiteren Verlauf ausgewertet. Zusätzlich werden die
Frakturmorphologie und die Dislokation bei den verschiedenen Frakturtypen analysiert. Ergebnisse. Insgesamt wurden 52 Patienten mit einer glenohumeralen Kombinationsfraktur identifiziert. Es fanden sich 26 (50\%) Typ-1-Frakturen (anteriore Glenoidrandfraktur/Tuberculum-majus-Fraktur), 20 (38\%) Typ-2-Frakturen (anteriore Glenoidrandfraktur/proximale Humerusfraktur), 4 (8\%) Typ-3-Frakturen (Fossa-glenoidalisFraktur/Tuberculum-majus-Fraktur) und 2 (4\%) Typ-4-Frakturen (Fossa-glenoidalisFraktur/proximale Humerusfraktur). In der Mehrzahl der Fälle $(n=25)$ wurden beide Verletzungen dieser kombinierten Frakturen operativ behandelt, in 15 Fällen wurden beide Frakturen konservativ behandelt, und bei 12 Patienten wurde nur eine der beiden Frakturen operiert. Komplikationen wurden in $21 \%$ der Fälle insbesondere auf der humeralen Seite festgestellt.

Schlussfolgerung. Glenohumerale Kombinationsfrakturen sind seltene Frakturmuster, wobei Typ 1 und Typ 2 am häufigsten vertreten sind. Die Indikationen orientieren sich an der Dislokation der jeweiligen Fragmente und können im Fall einer Op.Indikation in derselben Op. behandelt werden. Komplikationen werden dabei häufiger am Humerus festgestellt.

\section{Schlüsselwörter}

Fossa glenoidalis · Proximaler Humerus . Kombinationsfrakturen - Fossa glenoidalis . Glenoidrand patients aged 77 and 92 years who were treated with a reversed prosthesis). In four of the patients (15\%), only the anterior glenoid rim fracture was fixed (using an open approach in three cases and arthroscopically in one case) while the greater tuberosity was managed conservatively because of no or moderate displacement ( $\varnothing 1 \mathrm{~mm}, 0-3 \mathrm{~mm} ; n=2$ cranial displacement, $n=1$ posterior displacement). By contrast, in two patients (8\%) only the greater tuberosity was refixed while the glenoid rim fracture was treated nonoperatively because the glenoid rim lesion was overlooked in one case and because of mild displacement in the second case $(3 \mathrm{~mm}$, coronary plane; - Fig. 1). An overview of the different types of fractures and their respective treatment is given in - Fig. 2 .

The large glenoid rim fractures that were treated by surgery had a larger average medial displacement of $14 \mathrm{~mm}$ $(4-21 \mathrm{~mm})$ in contrast to the glenoid rim fractures that were treated nonoperatively with $6 \mathrm{~mm}$ on average $(0-14 \mathrm{~mm})$ in the coronary plane. Also, the greater tuberosity fractures that were treated operatively were more displaced $(\varnothing 7.6 \mathrm{~mm}$; $1-20 \mathrm{~mm}$ ), than those treated conservatively ( $22 \mathrm{~mm} ; 0-7 \mathrm{~mm}$ ). Two older patients (86 and 76 years of age) were treated nonoperatively despite having large displaced glenoid rim fractures (8 and $14 \mathrm{~mm}$ [coronary plane]; posteriorly displaced greater tuberosity fracture in one case $[7 \mathrm{~mm}]$ ) because of rejection of the recommended surgery and comorbidities. In one patient, only the 


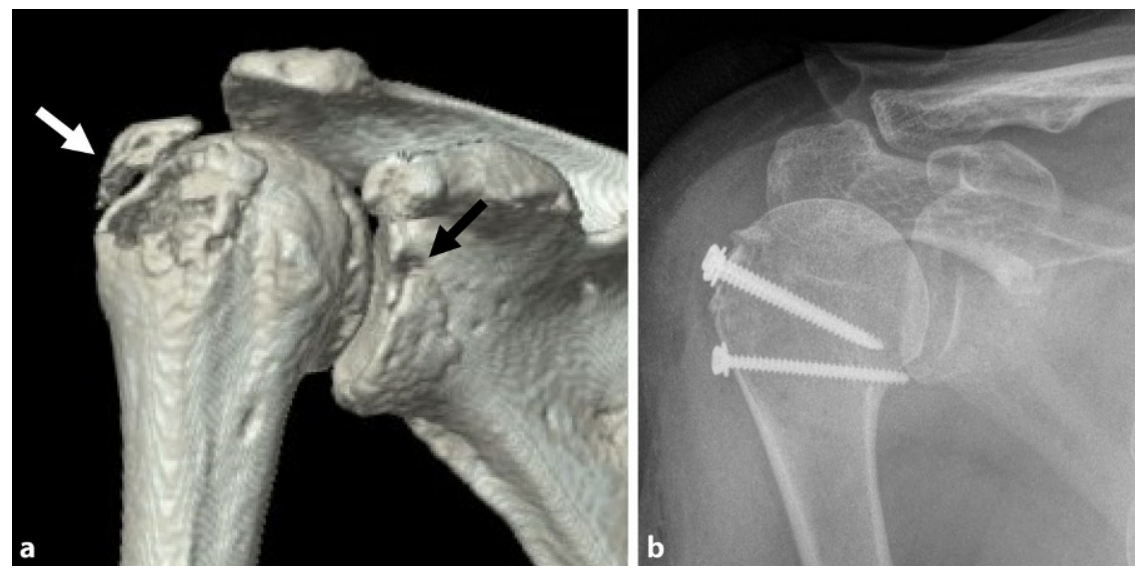

Fig. $1 \Delta$ a Three-dimensional CT of a 58-year-old female patient with type 1a glenohumeral combination fracture and displaced greater tuberosity (white arrow) with mild displacement of the anterior large glenoid rim fracture (black arrow). b Greater tuberosity treated via mini-open approach (screws with suture wiring); glenoid rim fracture treated nonoperatively (a.p.view)

greater tuberosity was fixed, leaving the medially displaced glenoid rim fracture $(13 \mathrm{~mm})$ to be managed nonoperatively, because the fracture was overlooked before (and during) the surgery (as mentioned earlier).

During the follow-up, complications were observed in four patients (15\%). There were two cases with a secondary displacement of a nonoperatively treated comminuted greater tuberosity (one after operative refixation of the glenoid and another after nonoperative treatment of the glenoid). The first showed a comminuted greater tuberosity with a slight cranial displacement of $1 \mathrm{~mm}$ on the initial radiographs and a secondary increase of the cranial displacement of $6 \mathrm{~mm}$ of the greater tuberosity was observed after 3 weeks (with continued nonoperative treatment and no further displacement on subsequent radiographs). In the second case, the (comminuted) greater tuberosity ( $3 \mathrm{~mm}$ cranial displacement) was observed with a secondary cranial displacement of $9 \mathrm{~mm}$ after 6 weeks but the patient declined further therapy. Furthermore, one patient suffered from a redislocation after refixation of only the glenoid rim fracture and presented with a chronic locked shoulder dislocation after 6 weeks but did not want to undergo further treatment because of advanced age (82) and comorbidities. One patient needed arthroscopy several months after nonoperative treatment of the combined glenohumeral fracture because of resid- ual pain; pathology of the long head of the biceps was found, which was addressed via tenodesis.

\section{Type 2}

In total, 20 patients (38\%) had a combination fracture of a glenoid rim fracture and a proximal humerus fracture. The average age of the patients was 63 years (47-82 years) including 11 female and nine male patients. In all cases, the trauma mechanism was a direct impact on the shoulder. The glenoid rim fracture displacement was $\varnothing 7 \mathrm{~mm}$ $(0-18 \mathrm{~mm})$ on average in the coronary plane and $4 \mathrm{~mm}(1-10 \mathrm{~mm})$ on average in the sagittal plane. The majority of the patients had complex proximal humerus fractures in combination with a large anterior glenoid rim fracture. The most frequently observed fractures were three-part fractures (including the greater tuberosity) in 13 (65\%) patients, followed by four-part fractures in four (25\%) cases, while there were only two (10\%) patients with a two-part fracture in the surgical neck.

In the majority of the patients, both injuries of the combined fractures were treated surgically ( $n=12,60 \%$; $\bullet$ Fig. 3 ). In these cases, the average medial displacement of the anterior glenoid rim fracture was $9 \mathrm{~mm}(2-18 \mathrm{~mm})$. In six patients (30\%), only the proximal humerus was treated operatively, while the anterior glenoid rim fracture was managed nonoperatively with an average glenoid rim fracture displacement of $5.5 \mathrm{~mm}$ (coronary plane, $0-13 \mathrm{~mm}$ ). In two of these patients, the glenoid rim lesion (4- and 6-mm medial displacement) was overlooked on the initial radiographs and treated nonoperatively. In one patient with a wide medially displaced $(13 \mathrm{~mm})$ glenoid rim fragment, the proximal humerus was treated surgically and the remaining glenoid rim fracture was managed nonoperatively, because of the individual decision of the treating surgeon.

In only two of all patients was nonoperative treatment of both lesions decided because of mildly displaced proximal humerus two-part and three-part fractures and a non- or mildly and medially displaced glenoid rim fracture (2 and $1 \mathrm{~mm}$ ). There was no case in which only the glenoid rim fracture was fixed leaving the proximal humerus fracture to be treated nonoperatively ( $\bullet$ Fig. 2).

Complications were found in six cases (30\%), particularly on the humeral side. In one patient in whom only the proximal humerus was fixed with plate osteosynthesis, the humeral head showed a decentricity on the postoperative followup radiographs together with a secondary displacement of the greater tuberosity. In a patient who was treated with a hemiarthroplasty on the humeral side (and screw fixation of the glenoid rim fracture), a secondary displacement of the refixed greater tuberosity with a partial resorption was observed. Periarticular calcifications at the humerus were found during follow-up in one patient. Partial avascular necrosis (AVN) was found in two patients on the humerus after plate osteosynthesis. One patient showed partial AVN of the humeral head and in another patient partial AVN of only the greater tuberosity was observed. On the glenoid side, screw loosening was found in one case but without further surgery or displacement of the fragment.

\section{Type 3 and 4}

Combined glenohumeral fractures with a glenoid fossa fracture are much less common than type 1 or type 2 fractures (- Fig.2). Type 3 and type 4 combination 


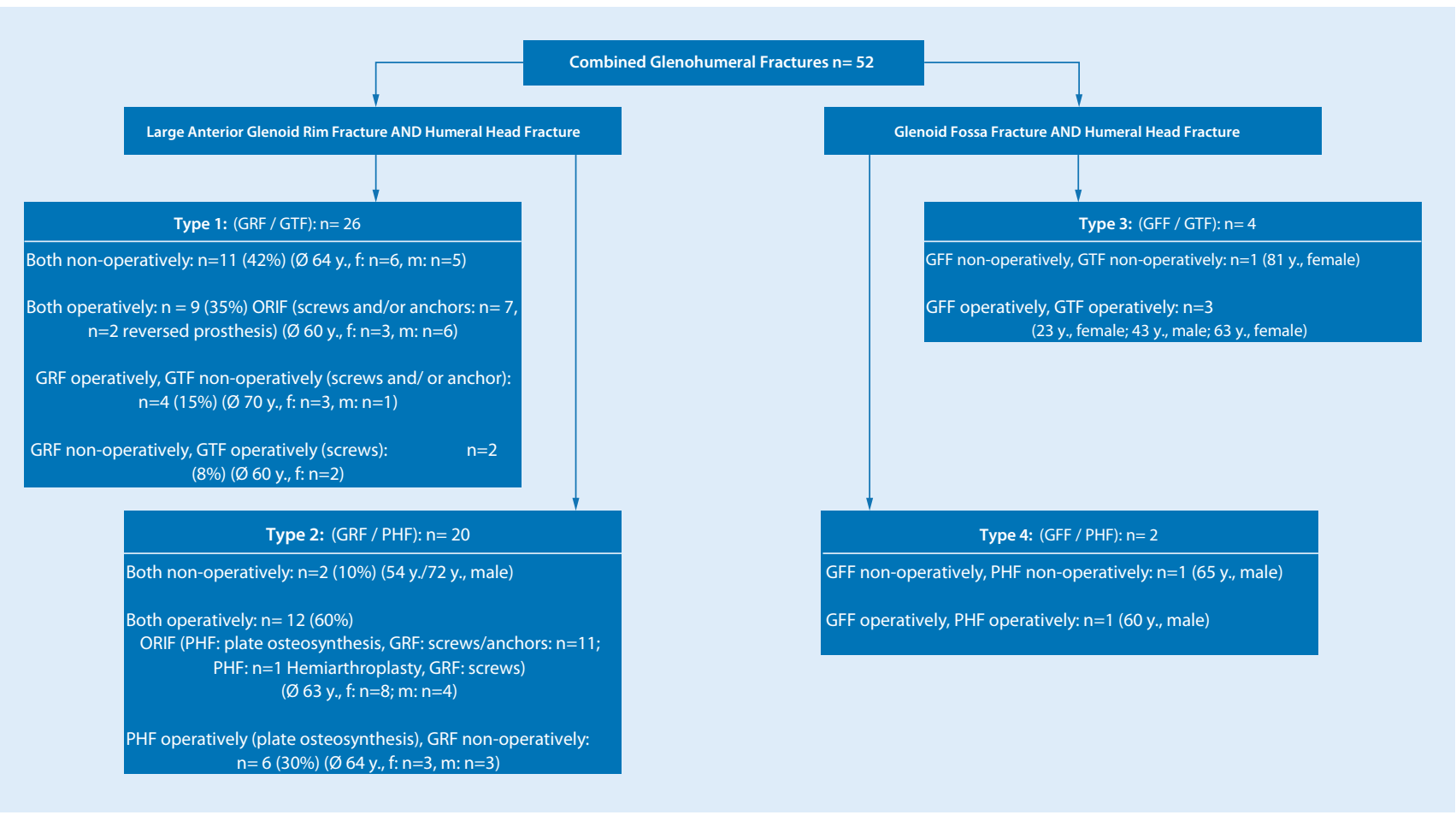

Fig. $2 \Delta$ Numeric distribution of combined glenohumeral fractures and their respective therapy. GRF glenoid rim fracture, GTF greater tuberosity fracture, PHF proximal humerus fracture, GFF glenoid fossa fracture, $f$ female, $m$ male, $y$ years of age, ORIF open reduction with internal fixation

fractures were found in only six cases (female $n=3$, male $n=3$; Ø 56 years, 23-81 years). In all cases, the trauma mechanisms were a direct fall on the shoulder but usually from some height (e.g., ladder, riding accident).

In the type 3 group $(n=4)$, greater tuberosity fractures comprised one fragment in one case, two fragments in one case, and they were comminuted in two patients. The greater tuberosity displacement was on average $\varnothing 3 \mathrm{~mm}(0-5 \mathrm{~mm}$; non-/mildly displaced [lateral]: $n=2$, moderately displaced [lateral]: $n=1$, displaced [cranial/dorsal]: $n=1$ ). Both proximal humerus fractures in the type 4 group $(n=2)$ were two-part fractures.

According to the Ideberg et al. classification of glenoid fractures, mostly type 2 glenoid fossa fractures $(n=5)$ were noted and in only one case $(n=1)$ was a type 5 glenoid fossa fracture found. The average medial displacement of the glenoid fossa fracture was $\varnothing 4 \mathrm{~mm}(0-7 \mathrm{~mm})$ in the coronary plane (intra-articular step-off) and the displacement in the sagittal plane ("fracture gap") was $\varnothing 4 \mathrm{~mm}$ (1-8 mm).
In two cases, the combined fractures were treated nonoperatively and in four patients the combined fractures were both treated operatively (- Figs. 2 and 4 ). All surgically treated glenoid fossa fractures $(n=4)$ were treated with plate osteosynthesis (open reduction and internal fixation [ORIF]) using a posterior approach. The operatively treated greater tuberosity fractures $(n=4)$ were fixed via a mini-open approach using screws $(n=3)$ or tension wiring $(n=1)$ and the surgically treated proximal humerus fracture $(n=1)$ was treated by plate osteosynthesis. As a complication, in the patient with a type 4 glenohumeral combination fracture, the proximal humerus plate showed a bending of the plate - after a likely secondary stress fracture during the posttreatment course on a followup radiograph 3 years after ORIF (of both lesions; - Fig. 5). The plate at the proximal humerus and the glenoid was subsequently removed. Further complications were not found in the type 3 and 4 groups.

The operatively treated glenoid fractures $(n=4)$ had a medial displacement of $5 \mathrm{~mm}(3-7 \mathrm{~mm})$ on average and a displacement in the sagittal plane of $\varnothing$ $5 \mathrm{~mm}(1-8 \mathrm{~mm})$. The operatively treated greater tuberosity fractures had a (cranial or lateral) displacement of $3 \mathrm{~mm}$ $(1-5 \mathrm{~mm})$ on average. Within the group of nonoperatively treated glenoid fossa fractures $(n=2)$, the medial displacement was 0 and $5 \mathrm{~mm}$ with a displacement in the sagittal plane of 2 and $6 \mathrm{~mm}$. Despite the significant displacement of the glenoid $(5 \mathrm{~mm}$ coronary plane $/ 6 \mathrm{~mm}$ sagittal plane) in one of these two patients, a nonoperative treatment was chosen because of advanced age (81 years; greater tuberosity fracture: $1 \mathrm{~mm}$ displaced laterally).

\section{Discussion}

Large anterior glenoid rim fractures with a concomitant fracture of the greater tuberosity (type 1) were most frequently seen at our hospital followed by combination fractures of the proximal humerus (type 2). The rarest glenohumeral fracture combinations were glenoid fossa fractures together with 

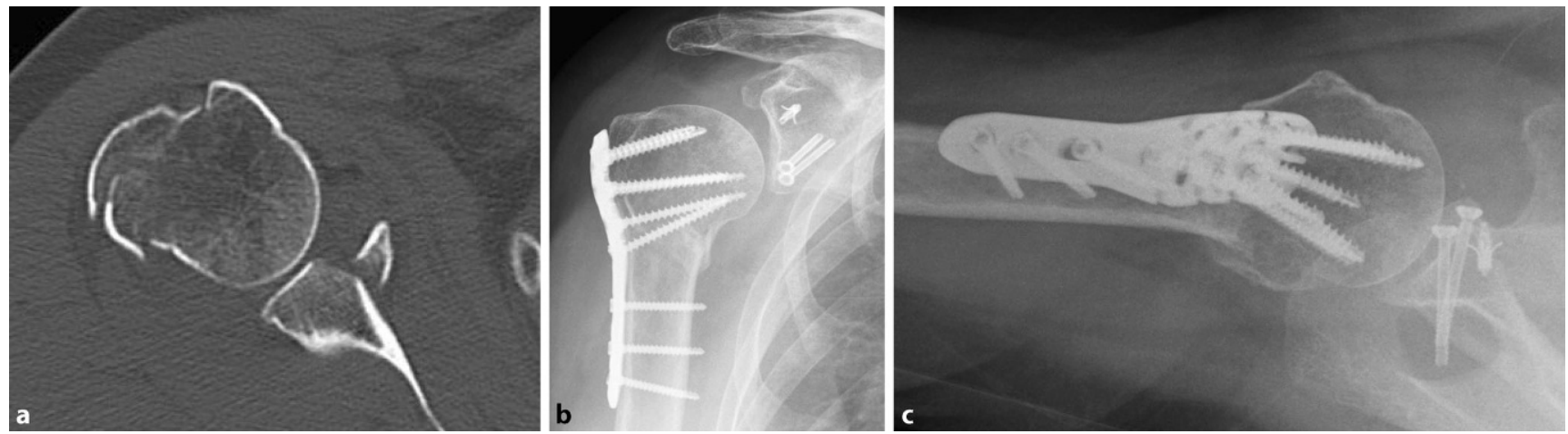

Fig. 3 A Type 2 glenohumeral combination fracture in a 59-year-old female patient with a three-part proximal humerus fracture (a, CT, axial view) 6 weeks after ORIF of both lesions; slight inferior decentricity after passive motion (b, a.p. view) but regular concentricity in the axial view (c)
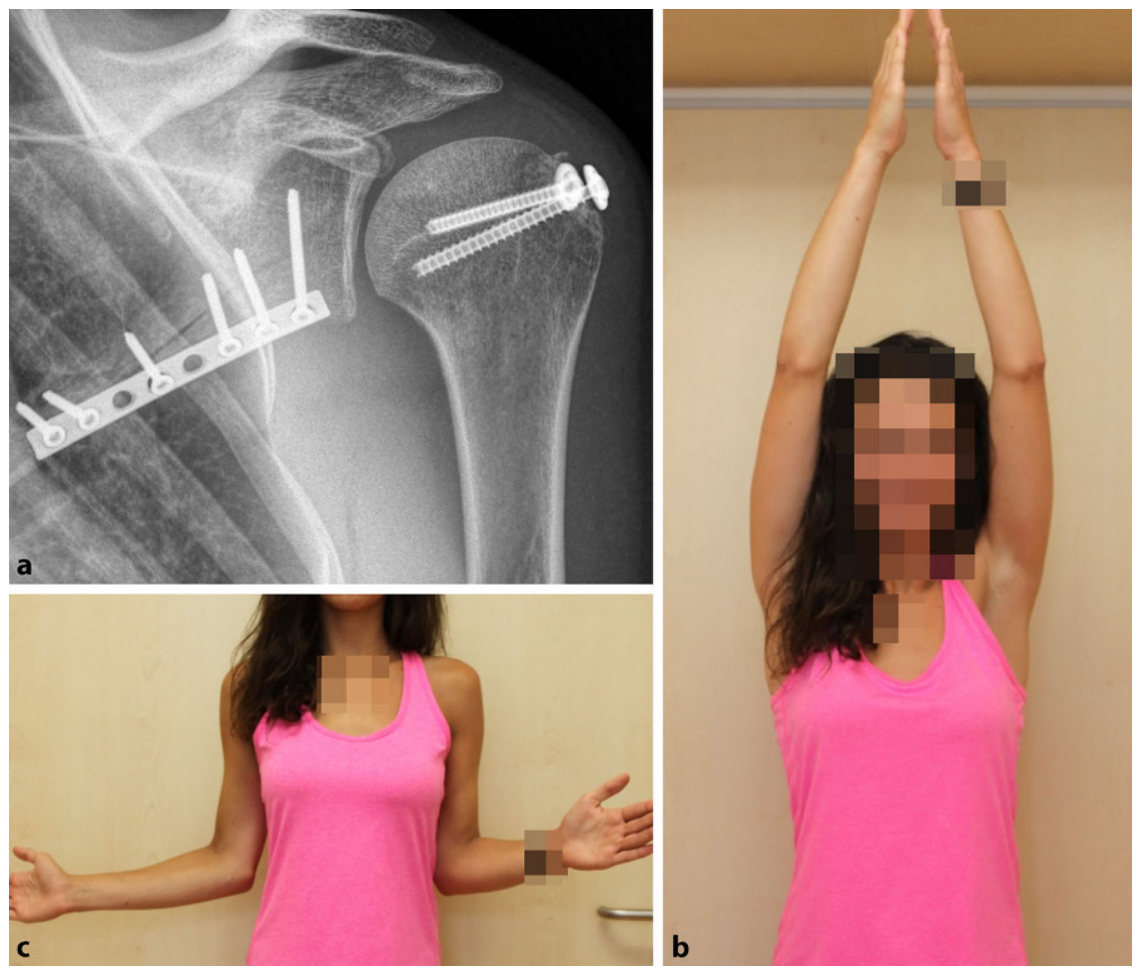

Fig. 4 \ A 23-year-old female patient with a type 3 combination fracture of the left shoulder after ORIF for a displaced glenoid fossa fracture (type 2, Ideberg et al. classification) and percutaneous fixation of the greater tuberosity (a, .p. view) with free range of motion in flexion/abduction (b) and internal rotation and only a slight residual deficit in external rotation 16 months after surgery (c)

a greater tuberosity fracture or a proximal humerus fracture. There are only few data available about the rare combined glenohumeral fractures in the literature. Especially in studies dealing with glenoid fractures, scapula body fractures, or first-time shoulder dislocations, occasional descriptions can be found about additional fractures of the humeral head mostly under "associated injuries."
In a study about the nonoperative treatment of large anterior glenoid rim fractures $(n=14)$, five cases with an additional nondisplaced greater tuberosity fracture were found and were all treated nonoperatively, but two of these patients with a fracture of the greater tuberosity had a loss of external rotation of $10^{\circ}$ and $20^{\circ}$, respectively [34]. Robinson et al. described 11 cases with a combined glenoid rim and greater tuberosity fracture (type 1a) in a large cohort of 538 patients with first-time traumatic anterior shoulder dislocations, which corresponds to $2 \%$ of all traumatic shoulder dislocations [43]. The re-instability rate of the whole collective was analyzed in the first 6 weeks and seven of the 11 combined fractures showed re-instability with subsequent ORIF. During the surgery, the authors estimated "restoration of shoulder stability" by testing of the full passive ROM. The authors describe restoration of stability during surgery after fixation of only the glenoid rim without fixation of the greater tuberosity in four of the cases. In the other three patients in whom stability could not be restored by fixing the glenoid only, fixation of the greater tuberosity was carried out. At 1 year after the surgery, "satisfactory functional scores" and no instability were reported [43]. In contrast to these data, no reinstability was found in our group of patients with type 1 fractures, in whom the combined fractures were both treated nonoperatively.

A few combination fractures have been reported in retrospective studies with the focus on either large operatively treated glenoid rim fractures $[33,39$, 51] or refixed greater tuberosity fractures [17]. In two studies dealing with operative treatment of large anterior glenoid rim fractures, one fracture of the greater tuberosity was fixed percutaneously during the same operation and an additional greater tuberosity fracture and a proximal humerus fracture were treated by ORIF $[33,51]$. In their study of 20 surgically treated (ORIF) anterior glenoid rim fractures, Osti et al. 


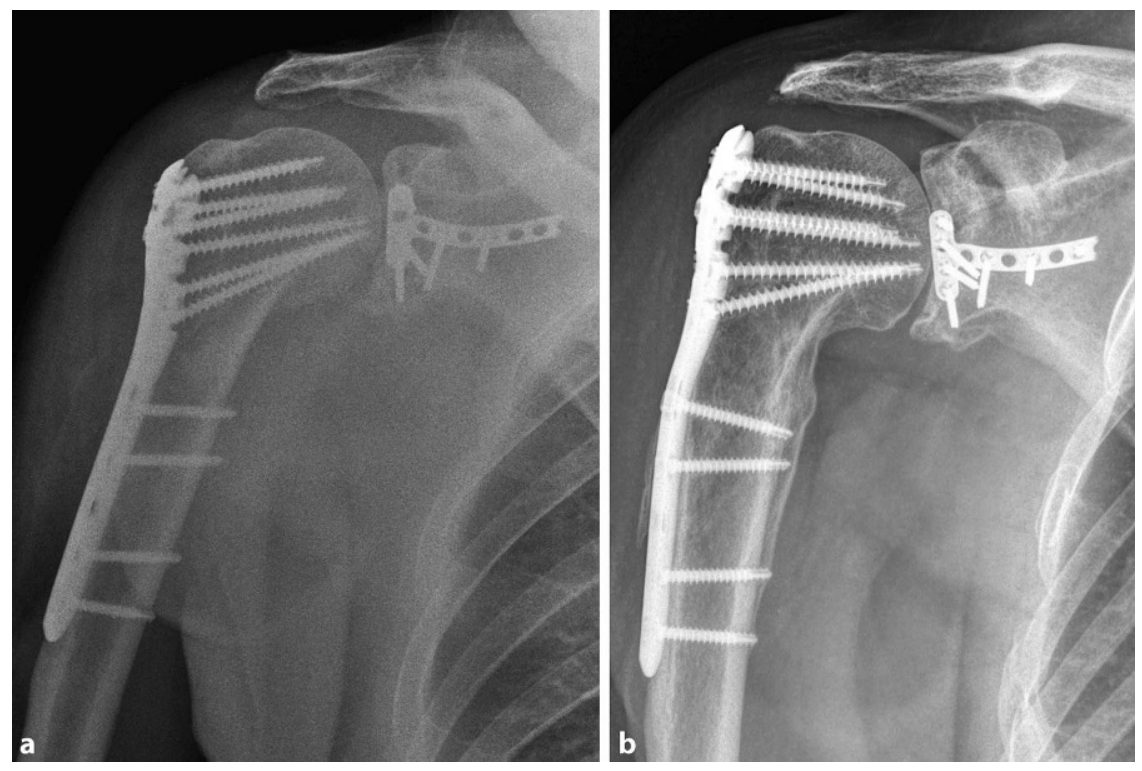

Fig. 5 a Type 4 combination fracture in a 60-year-old male patient after ORIF (a, a.p.view, intraoperative radiographs). After 3 years, a healed secondary fracture was observed more distally at the level of the sliding hole and a twisted proximal humerus plate with a more varus position (b, a.p. view)

found five patients with an associated fracture of the greater tuberosity and two patients with a concomitant proximal humerus fracture (both three-part fractures). Both proximal humerus fractures were (additionally) treated surgically (ORIF) and one of the greater tuberosity fractures was refixed because of "significant displacement." Three of the patients with concomitant injuries showed a restricted ROM presumably because of a less aggressive rehabilitation protocol [39].

In a study of arthroscopic refixation of greater tuberosity fractures, three type 1 combination fractures were found and the additional glenoid rim fractures were all treated with suture anchors. The authors describe early degenerative change of the glenoid rim and intermittent shoulder pain after 2 years [17].

Garofalo et al. published the only study $(n=26)$ of glenohumeral combination fractures (of type 1 and type 2) that were all treated by reversed prosthesis and additional bone grafting. The patients had overall excellent and good results at the final follow-up [13]. However, the number of proximal humerus fractures and only greater tuberosity fractures in their cohort of combination fractures is not listed explicitly and remains unclear. In terms of complications, only one case of superficial infection and two cases of heterotopic ossifications were found [13].

Concomitant fractures of the humeral head are more rarely described in the literature in combination with glenoid fossa fractures (type 3 and 4). Nork et al. described in their surgically treated patient cohort of 17 patients one case with a concomitant proximal humerus fracture, but no further information is given about that case [37]. Two further studies include a mixed cohort of intra- and extra-articular scapula fractures $(n=62$ [3] and $n=22$ [14]) and concomitant "humerus fractures" ( $n=7$ [3], $n=3$ [14]), but they are a mixed collective with extra-articular scapula fractures and it remains unclear whether humerus shaft fractures or proximal humerus fractures are involved [3, 14].

Type 1 glenohumeral combination fractures were most frequently seen at our hospital over the observation period (50\% of all combination fractures), followed by type 2 (38\%). Type 3 fractures were present in $8 \%$ of cases and type 4 in only $4 \%$. The incidence of the different glenoid fractures corresponds to the numerical distribution of the glenoid fractures in the literature, in which glenoid rim fractures are more frequently seen than glenoid fossa fractures [15, 45]. Interestingly, five $(83 \%)$ of the six glenoid fossa fractures were type 2 Ideberg et al. classification, which suggests a uniform traumatic pathomechanism of such combined glenohumeral fractures, because in isolated glenoid fossa fractures there is not such a clear distribution in favor of one fracture type [15, 22, 45].

The highest complication rate in our study was found after ORIF in type 2 combination fractures, followed by complications in type 1 fractures. The reason that only one complication was found in the type 3 and 4 fractures is probably due to the low number of cases in these both groups. It is noteworthy that most of the complications were found on the humeral side in type 1 (and type 4 ) but particularly in type 2 fractures. This corresponds to the results of studies of (isolated) proximal humerus fractures, which usually have higher complication rates after surgery (ORIF and hemiarthroplasty) than studies of operatively treated glenoid rim or glenoid fossa fractures $[5,18,24$, $25,27,29,30,38,39,44-46,50,53]$.

In one case of a type 1 combination fracture and in two cases of type 2 fractures, the anterior glenoid rim fracture was overlooked on the initial radiographs and only the greater tuberosity or the proximal humerus were treated surgically. Thus, the surgeon should be aware of the occurrence of glenohumeral combination fractures and should bear in mind to check the anterior sclerotic line of the glenoid [16] in order to exclude concomitant glenoid rim lesions.

\section{Limitations}

There are some limitations in the present study. The analysis included patient records but not clinical scores with a specific follow-up. Although most patients return for regular follow-up, some complications can presumably go unnoticed in the posttreatment course if they are lost to follow-up or treated at another hospital. The indications for surgery and the term "displaced" are not defined clearly in the literature. Therefore, the indications were not standardized and were partially based on the evaluation of the treating surgeon or, occasionally, on the individual wishes of the patient. 


\section{Practical conclusion}

- In glenohumeral combination fractures, both lesions should be considered individually regarding the indication for treatment based on the degree of displacement of the respective injury.

- Another decisive criterion is the concentricity of the humeral head in type 1 and type 3 fractures in which only the greater tuberosity is fractured.

- If necessary, both lesions can be addressed in one operation with the patient in the same position (e.g., beach-chair position; type 4 combination fractures are an exception to this and needed to be transfered from the lateral decubitus position [ORIF of the fossa glenoidalis] into beach-chair position [for ORIF of the proximal humerus]).

- Complications can occur mainly at the proximal humerus in contrast to the glenoid, which warrants regular radiographic follow-up.

- Clinical follow-up studies are needed to further differentiate the indications for treatment and the clinical prognosis of the different types of glenohumeral combination fractures.

\section{Corresponding address}

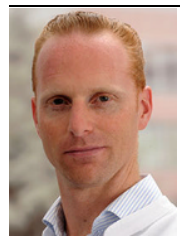

Dr. M. Königshausen General and Trauma Surgery, BG University Bergmannsheil, Ruhr University Bochum Bürkle-de-la-Camp Platz 1, 44789 Bochum, Germany matthias.koenigshausen@ bergmannsheil.de

\section{Compliance with ethical guidelines}

Conflict of interest M. Königshausen, E. Mempel, V. Rausch, J. Gessmann, T.A. Schildhauer, and D. Seybold declare that they have no competing interests.

This article does not contain any studies with human participants or animals performed by any of the authors.

Open Access This article is distributed under the terms of the Creative Commons Attribution 4.0 International License (http://creativecommons.org/licenses/by/
4.0/), which permits unrestricted use, distribution, and reproduction in any medium, provided you give appropriate credit to the original author(s) and the source, provide a link to the Creative Commons license, and indicate if changes were made.

\section{References}

1. Agudelo J, Schurmann $M$, Stahel $P$, Helwig $P_{,}$ Morgan SJ, Zechel W, Bahrs C, Parekh A, Ziran B, Williams A, Smith W (2007) Analysis of efficacy and failure in proximal humerus fractures treated with locking plates. JOrthop Trauma 21:676-681

2. Anavian J, Gauger EM, Schroder LK, Wijdicks CA, Cole PA (2012) Surgical and functional outcomes after operative management of complex and displaced intra-articular glenoid fractures. J Bone Joint Surg Am 94:645-653

3. Armstrong CP, Van der Spuy J (1984) The fractured scapula: importance and management based on a series of 62 patients. Injury 15:324-329

4. Bigliani LU, Newton PM, Steinmann SP, Connor PM McLlveen SJ (1998) Glenoid rim lesions associated with recurrent anterior dislocation of the shoulder Am J Sports Med 26:41-45

5. Boons HW, Goosen JH, van Grinsven S, van Susante JL, van Loon CJ (2012) Hemiarthroplasty for humeral four-part fractures for patients 65 years and older: a randomized controlled trial. Clin Orthop Relat Res 470:3483-3491

6. Brorson S, Frich LH, Winther A, Hrobjartsson A (2011) Locking plate osteosynthesis in displaced 4-part fractures of the proximal humerus. Acta Orthop 82:475-481

7. Brunner F, Sommer C, Bahrs C, Heuwinkel R, Hafner C, Rillmann P, Kohut G, Ekelund A, Muller M, Audige $L$, Babst $R$ (2009) Open reduction and internal fixation of proximal humerus fractures using a proximal humeral locked plate: a prospective multicenter analysis. J Orthop Trauma 23:163-172

8. Codman EA (1934) The shoulder. Rupture of the supraspinatus tendon and other lesions in or about the subacromial bursa. Thomas Todd, Boston, pp 262-293

9. Cole PA, Freeman G, Dubin JR (2013) Scapula fractures. Curr Rev Musculoskelet Med 6:79-87

10. Euler E, Habermeyer P, Kohler W, Schweiberer L (1992) Scapula fractures-classification and differential therapy. Orthopade 21:158-162

11. Fjalestad T, Hole MO, Hovden IA, Blucher J, Stromsoe K (2012) Surgical treatment with an angular stable plate for complex displaced proximal humeral fractures in elderly patients: a randomized controlled trial. J Orthop Trauma 26:98-106

12. Freijzer PL, van Geene $A R$, van der Woude $H J$, Willems WJ (2012) Infraglenoid tubercle avulsion and greater tuberosity fracture resulting from traumatic glenohumeral anterior dislocation: a case report. J Orthop Trauma 26:e1-e3

13. Garofalo R, Brody F, Castagna A, Ceccarelli E Krishnan SG (2016) Reverse shoulder arthroplasty with glenoid bone grafting for anterior glenoid rim fracture associated with glenohumeral dislocation and proximal humerus fracture. Orthop Traumatol Surg Res 102:989-994

14. Herrera DA, Anavian J, Tarkin IS, Armitage BA, Schroder LK, Cole PA (2009) Delayed operative management of fractures of the scapula. J Bone Joint Surg Br 91:619-626

15. Ideberg R, Grevsten S, Larsson S (1995) Epidemiology of scapular fractures. Incidence and classification of 338 fractures. Acta Orthop Scand 66:395-397

16. Jankauskas L, Rudiger HA, Pfirrmann CW, Jost B, Gerber C (2010) Loss of the sclerotic line of the glenoid on anteroposterior radiographs of the shoulder: a diagnostic sign for an osseous defect of the anterior glenoid rim. J Shoulder Elbow Surg 19:151-156

17. Ji JH, Jeong JJ, Kim YY, Lee SW, Kim DY, Park SE (2017) Clinical and radiologic outcomes of arthroscopic suture bridge repair for the greater tuberosity fractures of the proximal humerus. Arch Orthop Trauma Surg 137:9-17

18. Jost B, Spross C, Grehn H, Gerber C (2013) Locking plate fixation of fractures of the proximal humerus: analysis of complications, revision strategies and outcome. J Shoulder Elbow Surg 22:542-549

19. Jung SW, Shim SB, Kim HM, Lee JH, Lim HS (2015) Factors that influence reduction loss in proximal humerus fracture surgery. J Orthop Trauma 29:276-282

20. Katthagen JC, Lutz O, Voigt C, LillH, Ellwein A (2018) Cement augmentation of humeral head screws reduces early implant-related complications after locked plating of proximal humeral fractures. Obere Extremität 13:123-129

21. Königshausen M, Coulibaly V, Nicolas V, Schildhauer TA, Seybold D (2013) Non-operative treatment of antero-inferior glenoid rim fractures (Bankart fracture): preliminary results. Obere Extremität 8:96-102

22. Königshausen $M$, Coulibaly MO, Nicolas $V$ Schildhauer TA, Seybold D (2016) Results of nonoperative treatment of fractures of the glenoid fossa. Bone Joint J 98-B:1074-1079

23. Königshausen M, Gessmann J, Seybold D, Schildhauer TA (2016) Konservative Therapie der proximalen Humerusfraktur. Orthop Unfallchir Up2date 11:483-500

24. Königshausen M, Kubler L, Godry H, Citak M, Schildhauer TA, Seybold D (2012) Clinical outcome and complications using a polyaxial locking plate in the treatment of displaced proximal humerus fractures. A reliable system? Injury 43:223-231

25. Königshausen $M$, Rausch $V$, Mempel $E$, von Glinski A, UII C, Bernstorff M, Schildhauer T, Seybold D, Gessmann J (2018) Bilateral proximal humerus fracture - a rare combination with a high complication rate after surgery. Z Orthop Unfall. https://doi.org/10.1055/a-0619-6400

26. Königshausen M, Seybold D, Gessmann J, Schildhauer TA (2014) Klassifikationen und therapeutische Indikationen bei Scapulafrakturen. Trauma Berufskrankh 16:6-12

27. Königshausen $M$, Thierbach A, Kubler L, Gessmann J, Godry H, Gothner M, Schildhauer TA, Seybold D (2015) Surgical treatment of 3-and 4-part fractures of the humeral head using a polyaxial-locking plate: results and patient satisfaction. Z Orthop Unfall 153:51-58

28. Kraus N, Gerhardt C, Haas N, Scheibel M (2010) Conservative therapy of antero-inferior glenoid fractures. Unfallchirurg 113:469-475

29. Lantry JM, Roberts CS, Giannoudis PV (2008) Operative treatment of scapular fractures: a systematic review. Injury 39:271-283

30. Leung KS, Lam TP, Poon KM (1993) Operative treatment of displaced intra-articular glenoid fractures. Injury 24:324-328

31. Lill H, Hepp P, Rose T, Konig K, Josten C (2004) The angle stable locking-proximal-humerusplate (LPHP) for proximal humeral fractures using a small anterior-lateral-deltoid-splitting 
approach-technique and first results. Zentralbl Chir 129:43-48

32. Lind T, Kroner K, Jensen J (1989) The epidemiology of fractures of the proximal humerus. Arch Orthop Trauma Surg 108:285-287

33. Maier D, Izadpanah K, Bayer J, Langenmair ER, Ogon P, Sudkamp NP, Jaeger M (2017) Influencing factors and complications in open treatment of acute anterior glenoid rim fractures. Unfallchirurg 120:320-328

34. Maquieira GJ, Espinosa N, Gerber C, Eid K (2007) Non-operative treatment of large anterior glenoid rim fractures after traumatic anterior dislocation of the shoulder. JBone Joint Surg Br 89:1347-1351

35. Neer CS 2nd (1970) Displaced proximal humeral fractures. I. Classification and evaluation. J Bone Joint Surg Am 52:1077-1089

36. Neer CS 2nd (1970) Displaced proximal humeral fractures. II. Treatment of three-part and four-part displacement. J Bone Joint Surg Am 52:1090-1103

37. Nork SE, Barei DP, Gardner MJ, Schildhauer TA, Mayo KA, Benirschke SK (2008) Surgical exposure and fixation of displaced type IV, V, and VI glenoid fractures. J Orthop Trauma 22:487-493

38. Ockert B, Braunstein V, Kirchhoff C, Korner M Kirchhoff S, Kehr K, Mutschler W, Biberthaler P (2010) Monoaxial versus polyaxial screw insertion in angular stable platefixation of proximal humeral fractures: radiographic analysis of a prospective randomized study. JTrauma 69:1545-1551

39. Osti M, Gohm A, Benedetto KP (2009) Results of open reconstruction of anterior glenoid rim fractures following shoulder dislocation. Arch Orthop Trauma Surg 129:1245-1249

40. Plachel F, Schanda JE, Ortmaier R, Auffarth A, Resch H, Bogner R (2017) The "triple dislocation fracture": anterior shoulder dislocation with concomitant fracture of the glenoid rim, greater tuberosity and coracoid process - a series of six cases. J Shoulder Elbow Surg 26:e278-e285

41. Plecko M, Kraus A (2005) Internal fixation of proximal humerus fractures using the locking proximal humerus plate. Oper Orthop Traumatol 17:25-50

42. Resch $\mathrm{H}$, Tauber $M$, Neviaser RJ, Neviaser AS, Majed A, Halsey T, Hirzinger C, Al-Yassari G, Zyto K, Moroder P (2015) Classification of proximal humeral fractures based on a pathomorphologic analysis. J Shoulder Elbow Surg. https://doi.org/ 10.1016/j.jse.2015.08.006

43. Robinson CM, Kelly M, Wakefield AE (2002) Redislocation of the shoulder during the first six weeks after a primary anterior dislocation: risk factors and results of treatment. J Bone Joint Surg Am 84-A:1552-1559

44. Roderer G, Erhardt J, Kuster M, Vegt P, Bahrs C, Kinzl L, Gebhard F (2011) Second generation locked plating of proximal humerus fractures-a prospective multicentre observational study. Int Orthop 35:425-432

45. Schandelmaier $P$, Blauth M, Schneider C, Krettek $C$ (2002) Fractures of the glenoid treated by operation. A 5- to 23-year follow-up of 22 cases. JBone Joint Surg Br 84:173-177

46. Scheibel M, Hug K, Gerhardt C, Krueger D (2016) Arthroscopic reduction and fixation of large solitary and multifragmented anterior glenoid rim fractures. J Shoulder Elbow Surg 25:781-790

47. Scheibel M, Kraus N, Gerhardt C, Haas NP (2009) Anterior glenoid rim defects of the shoulder. Orthopade 38:41-53

48. Schliemann B, Heilmann LF, Raschke MJ, Lill H, Katthagen JC, Ellwein A (2018) Isolated fractures of the greater tuberosity: When are they treated conservatively?: A baseline study. Obere Extremität 13:106-111

49. Schliemann B, Siemoneit J, Theisen C, Kosters C Weimann A, Raschke MJ (2012) Complex fractures of the proximal humerus in the elderly-outcome and complications after locking plate fixation. Musculoskelet Surg 96(Suppl 1):S3-S11

50. Sudkamp N, Bayer J, Hepp P, Voigt C, Oestern H, Kaab M, Luo C, Plecko M, Wendt K, Kostler W, Konrad G (2009) Open reduction and internal fixation of proximal humeral fractures with use of the locking proximal humerus plate. Results of a prospective, multicenter, observational study. JBone Joint Surg Am 91:1320-1328

51. Tauber M, Moursy M, Eppel M, Koller H, Resch H (2008) Arthroscopic screw fixation of large anterio glenoid fractures. Knee Surg Sports Traumatol Arthrosc 16:326-332

52. te Slaa RL, Verburg H, Marti RK (2001) Fracture of the coracoid process, the greater tuberosity, and the glenoid rim after acute first-time anterior shoulder dislocation: a case report. J Shoulder Elbow Surg 10:489-492

53. Voigt C, Geisler A, Hepp P, Schulz AP, Lill H (2011) Are polyaxially locked screws advantageous in the plate osteosynthesis of proximal humeral fractures in the elderly? A prospective randomized clinical observational study. J Orthop Trauma 25:596-602

54. Wiedemann E (2004) Fractures of the scapula. Unfallchirurg 107:1124-1133 